\title{
Seminal Plasma Promotes Lesion Development in a Xenograft Model of Endometriosis
}

\author{
Jonathan T. McGuane, ${ }^{*}$ Katherine M. Watson, * Jamie Zhang, ${ }^{*}$ M. Zahied Johan, ${ }^{*}$ Zhao Wang, ${ }^{*}$ Gabriel Kuo, ${ }^{*}$
}

David J. Sharkey, ${ }^{*}$ Sarah A. Robertson, ${ }^{*}$ and M. Louise Hull ${ }^{* \dagger \ddagger}$

\begin{abstract}
From the Robinson Research Institute and Discipline of Obstetrics and Gynaecology, * School of Paediatrics and Reproductive Health, University of Adelaide, Adelaide, South Australia; the Department of Obstetrics and Gynaecology, ${ }^{\dagger}$ Women's and Children's Hospital, North Adelaide, Adelaide, South Australia; and the Fertility SA IVF Unit, ${ }^{\ddagger}$ Adelaide, South Australia, Australia
\end{abstract}

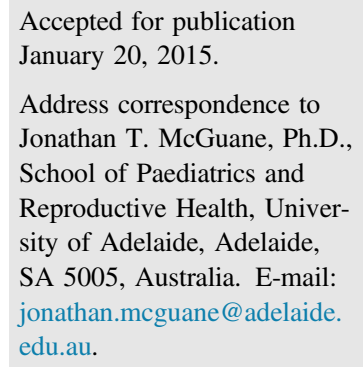

\begin{abstract}
The factors that predispose one-tenth of reproductive-aged women to endometriosis are poorly understood. We determined that genetic deficiency in transforming growth factor $\beta 1$ impairs endometriosislike lesion growth in mice. Given that seminal plasma is an abundant source of transforming growth factor $\beta$, we evaluated the effect of exposure to seminal plasma on the growth of endometrial lesions. Human endometrial explants were exposed to seminal plasma or to control medium before transfer to Prkdc scid mutant (severe combined immunodeficient) mice. Xenografts exposed to seminal plasma showed an eightfold increase in volume and a 4.3-fold increase in weight after 14 days. These increases were associated with increased proliferation of endometrial epithelial cells and enhanced survival and proliferation of human stromal cells compared with those in control lesions, in which human stromal cell persistence was negligible. Although the distribution of macrophages was altered, their number and activation status did not change in response to seminal plasma. Seminal plasma stimulated the production of a variety of cytokines in endometrial tissue, including growth-regulated oncogene, granulocyte macrophage colony-stimulating factor, and IL-1 $\beta$. These data suggest that seminal plasma enhances the formation of endometriosis-like lesion via a direct effect on endometrial cell survival and proliferation, rather than via macrophage-mediated mechanisms. These findings raise the possibility that endometrial exposure to seminal plasma could contribute to endometriotic disease progression in women. (Am J Pathol 2015, 185: 1409-1422; http://dx.doi.org/10.1016/j.ajpath.2015.01.010)
\end{abstract}

Endometriosis afflicts $10 \%$ of reproductive-aged women and is defined by the presence of extrauterine endometrial tissue, usually in the pelvic cavity. ${ }^{1}$ Current pharmacological therapies suppress endometriotic lesions and can ameliorate the symptoms of dysmenorrhea and chronic pelvic pain but are associated with significant side effects. Furthermore, the surgical excision of endometriotic lesions is associated with high recurrence rates of $40 \%$ to $50 \%$ at 5 years postsurgery. ${ }^{2}$ Women with endometriosis are also more likely to have difficulty conceiving, suffer depression, and be at increased risk for developing cancer ${ }^{3-6}$ and autoimmune disorders. ${ }^{7}$ Despite the high financial and social burdens of endometriosis, the etiology and pathophysiological processes underlying the disease remain unclear. ${ }^{8}$

Sampson's theory postulates that endometrial fragments in menstrual fluid pass in a retrograde manner through the fallopian tubes before attaching to and growing at ectopic sites. ${ }^{9}$ However, this theory does not explain why only $10 \%$ of women develop endometriosis, when retrograde menstruation occurs in up to $90 \%$ of women. ${ }^{1}$ Genetic loci that confer a risk for endometriosis have been identified, ${ }^{10}$ and various environmental, inflammatory, and immunological factors are implicated. The relative contribution of these and other causal factors remains to be established.

\footnotetext{
Supported by a Ballentyne Medical and Surgical Research Grant from the A.J. and J.S. Ballentyne Trust (M.L.H.), NHMRC Early Career Fellowship 44110997 (Z.W.), and National Health and Medical Research Council project grant APP1013950 (M.L.H.).

J.T.M. and K.M.W. contributed equally to this work.

Disclosures: None declared.
} 
Transforming growth factor (TGF)- $\beta 1$ is a multifunctional cytokine that is elevated in endometriotic lesions, serum, and peritoneal fluid in women with endometriosis..$^{11-13}$ When human tissue fragments were transferred to immunocompromised mice with a null mutation in $T g f b l$, smaller ectopic endometriosis-like lesions developed compared with those in wild-type controls, showing that TGF- $\beta 1$ bioavailability is a key determinant of lesion growth. ${ }^{14}$

Seminal plasma, the acellular fraction of seminal fluid, contains several cytokines, including very high concentrations of TGF- $\beta 1$, TGF- $\beta 2$, and TGF- $\beta 3 .{ }^{15}$ Seminal plasma injected i.p. increased cellular proliferation, angiogenesis, and tissue remodeling when human cervical adenocarcinoma cells were injected s.c. into nude mice. ${ }^{16}$ In vitro experiments have demonstrated increased proliferation of human endometrial epithelial cells after the addition of seminal plasma to culture media. ${ }^{17,18}$ This finding suggests the possibility that in women, seminal plasma exposure might enhance epithelial cell proliferation in retrograde menstrual endometrium, contributing to the development or progression of endometriosis.

Histological analysis indicates that endometriosis-like lesions progress from an acute inflammatory state, with neutrophil and early macrophage infiltration, to a healing and remodeling phenotype, in which macrophage and myofibroblast activity predominates. ${ }^{19}$ In an acute inflammatory response, phagocytic macrophages display classic (M1) activation markers such as $\mathrm{C}-\mathrm{C}$ chemokine receptor (CCR)-7 and produce factors such as nitric oxide (iNOS). ${ }^{20}$ To prevent uncontrolled classic activation, phagocytic tags from dying cells alternatively activate macrophages via enhanced TGF- $\beta$ signaling. ${ }^{21}$ These M2 macrophages display the alternative activation marker macrophage mannose receptor (MMR/CD206), scavenge cellular debris, and promote tissue remodeling, angiogenesis, and repair. ${ }^{20}$

In a mouse model, $\mathrm{M} 2$ macrophage activity promoted, and M1 macrophage activity suppressed, endometriosis-like lesion development. ${ }^{22}$ Additionally, in TGF- $\beta 1$-deficient mice, fewer macrophages were identified in ectopic endometrial lesions, suggesting that altered macrophage activity may have contributed to lesion repression. The high levels of TGF- $\beta 1$ in seminal plasma could enhance lesion development by promoting an M2 macrophage healing response in ectopic endometrial tissues.

In cervical and endometrial tissues exposed to seminal plasma, TGF- $\beta 1$ activates the heterotetrameric TGF- $\beta$ R $1 /$ TGF$\beta R 2$ receptor complex, leading to the up-regulation of several cytokines and chemokines, including granulocyte macrophage (GM) colony-stimulating factor (CSF), IL-1 $\beta$, IL-6, IL-8, monocyte chemotactic protein 1 , macrophage inflammatory protein $1 \alpha$, and leukemia inhibitory factor. ${ }^{23-25}$ These cytokines and chemokines recruit endometrial macrophages and dendritic cells to activate regulatory $\mathrm{T}$ cells and create a tolerogenic environment for an implanting embryo. ${ }^{19}$ Thus, it is plausible that seminal plasma-exposed endometrial tissue in retrograde menstrual fluid is more likely to escape immune surveillance, attach, and proliferate at an ectopic site in response to these chemokines.
We hypothesized that exposure to seminal plasma enhances the development of endometriotic lesions via either a direct proliferative effect on endometrial cells or by increased M2 macrophage-directed healing and repair. Additionally, we hypothesized that alterations in endometrial cytokine profile induced by seminal plasma underpin these effects. A xenograft mouse model was used to test the effect of direct endometrial exposure to seminal plasma on endometriosis-like lesion growth in vivo. Immunohistochemistry (IHC) analysis was used for quantifying the effect of seminal plasma on the cellular composition and activation status of macrophages in human endometrial explants and xenografts recovered from immunocompromised mice. Finally, we explored seminal plasma-induced cytokine mediators that may influence endometriotic lesion development in human endometrial explant cultures.

\section{Materials and Methods}

\section{Ethics Approval}

Approval for the use of human seminal plasma was obtained from the human ethics committees of St. Andrew's Hospital (Adelaide, SA, Australia), the University of Adelaide (Adelaide, SA, Australia), and the North Western Adelaide Health Service (Adelaide, SA, Australia) (REC 1394/03/ 08). The use of human endometrial tissue was approved by the human ethics committees of the Children, Youth and Women's Health Service (Adelaide, SA, Australia) (REC 2280/5/13). Animal experiments were approved by the animal ethics committees of the University of Adelaide (M-2012-080) and the Children, Youth and Women's Health Service (AE 838/4/14), and conducted in accordance with the Australian Code of Practice for the Care and Use of Animals for Scientific Purposes. ${ }^{26}$

\section{Seminal Plasma Collection}

Human seminal plasma was obtained from the male partners, aged 36 to 52 years $(n=6)$, of women undergoing treatment for female-factor infertility at Fertility SA (St. Andrew's Hospital) and healthy-proven fertile men $(n=4)$. Sperm analysis was conducted according to the recommendations of the World Health Organization, and samples were included only if all parameters were consistent with normal values in the World Health Organization Laboratory Manual for the Examination and Processing of Human Semen. ${ }^{27}$ None of the samples displayed leukospermia or were obtained from men taking immune-deviating drugs. After liquefaction, each sample was centrifuged at $10,000 \times g$ for 10 minutes at room temperature within 1 hour of ejaculation. The seminal plasma supernatant was then aspirated and frozen at $-80^{\circ} \mathrm{C}$. Equal portions of seminal plasma were subsequently thawed and pooled (to minimize the effect of variation in cytokine levels between individual ${ }^{25}$ ), aliquoted, and stored at $-80^{\circ} \mathrm{C}$. Our 
previous experience indicates that seminal plasma prepared in this way retains full bioactivity (unpublished data).

\section{Collection of Human Endometrial Tissue}

Endometrial biopsy samples $(n=4)$ of normal histological appearance appropriate for cycle phase were collected from women aged 36 to 40 years using Pipelle suction curettage (Pipelle de Cornier, Laboratoire C.C.D., Paris, France) during diagnostic laparoscopy for infertility. Exclusion criteria included the use of hormonal contraceptives in the 3 months before surgery, or surgery for gynecological cancer. No participant had endometriosis; two were in the proliferative phase and two were in the secretory phase of the cycle. Previous work suggests cycle phase has little impact on the growth of the resulting endometriosis-like lesions (unpublished data). A separate series of endometrial biopsies was collected from five women in the secretory phase for studies of macrophage phenotype. These patients were undergoing hysteroscopy and endometrial biopsy and their endometriosis status was not determined; however, all were asymptomatic.

The tissue was placed in phenol red-free Dulbecco's modified Eagle's medium:F12 (Sigma-Aldrich, Castle Hill, NSW, Australia) with $1 \%$ each insulin-transferrin-selenium-X supplement and penicillin/streptomycin (both, Life Technologies, Mulgrave, VIC, Australia), 0.1\% Ex-Cyte (Merck Millipore, Kilsyth, VIC, Australia), and $10 \mathrm{nmol} / \mathrm{L} 17 \beta$-estradiol (Sigma-Aldrich) as previously described. ${ }^{14}$ Tissues were cut into approximately $1 \mathrm{~mm}^{3}$ fragments, placed into multiwell plates ( 15 fragments/well), and incubated for 24 hours in media alone or in media containing $10 \%$ seminal plasma.

\section{Mice}

Female mice homozygous for the Prkdc scid mutation (severe combined immunodeficiency) were purchased from Laboratory Animal Services (University of Adelaide) at 5 weeks of age. Mice were housed under controlled light conditions (12-hour light:dark cycle) with ad libitum access to a standard diet and sterilized water. At 6 weeks of age, mice were anesthetized with $1.5 \%$ isoflurane (Veterinary Companies of Australia, Artarmon, NSW, Australia) and bilaterally ovariectomized via a single mid-dorsal incision. A 60-day release $1.5 \mathrm{mg} 17 \beta$-estradiol pellet (Innovative Research, Sarasota, FL) was placed s.c. in the left flank via the same incision. Mepivicaine $(0.02 \%$; Ceva Animal Health, Glenorie, NSW, Australia) was administered at the incision site immediately after surgery. Buprenorphine $(16 \mathrm{mg} / \mathrm{mL}$; Reckitt Benckiser, West Ryde, NSW, Australia) was given at $0.05 \mathrm{~mL}$ per $10 \mathrm{~g}$ body weight for 12 hours postoperatively for further analgesia as needed.

One to two weeks after ovariectomy, mice were anesthetized using isoflurane, and endometrial fragments were injected s.c ventrally. Mice were randomly allocated to receive human endometrial tissue that had been incubated with $10 \%$ seminal plasma for 24 hours $(n=10$ mice $)$ or control human endometrial tissue that had been incubated in media only for 24 hours $(n=11$ mice). Preliminary studies of cytokine responses indicated that these conditions were optimal (data not shown), consistent with previous in vitro ${ }^{17,23}$ and in vivo work. ${ }^{28,29}$ The seminal plasma concentration used represents an estimate of the highest possible physiologically relevant concentration in the uterus. Each mouse received 15 tissue fragments (ie, the tissue contents of 1 seminal plasma-treated or control culture well) from one patient as previously described. ${ }^{30}$ The number of mice receiving transplanted tissue from a single donor varied depending on the size of the biopsy sample, but each biopsy sample was distributed approximately equally between the groups.

Fourteen days post - endometrial tissue injection, mice were administered $100 \mu \mathrm{L}$ of $10 \mathrm{mg} / \mathrm{mL}$ 5-bromo-2'-deoxyuridine (BrdU) and 5-fluoro-2'-deoxyuridine mixture (Sigma-Aldrich) i.p. and euthanized 1 hour later with $400 \mu \mathrm{L}$ 2,2,2tribromoethanol (Sigma-Aldrich) i.p. Endometriosis-like lesions were measured (length $\times$ width $\times$ depth) using calipers, then dissected, removed, and weighed in a blinded fashion (K.M.W.) (Figure 1A). Tissues were transferred to $4 \%$ paraformaldehyde for 24 hours, followed by washing in phosphatebuffered saline and immersion in $70 \%$ ethanol. Tissues were dehydrated in an ascending ethanol series and transferred to xylene, then embedded in paraffin before sectioning at $5 \mu \mathrm{m}$.

\section{In Vitro Experiments}

Portions of the same endometrial biopsies obtained for in vivo studies were used for analyzing cytokine production in response to seminal plasma. The additional endometrial tissues collected were prepared in triplicate for the study of macrophage phenotype in explant culture. In both experiments, an equal number of tissue fragments $\left(1 \mathrm{~mm}^{3}\right)$ were treated in Nunclons Surface multiwell plates (Thermo Scientific, Scoresby, VIC, Australia) with media containing $10 \%$ seminal plasma or media alone. Additional control wells for cytokine studies contained media with $10 \%$ seminal plasma but no tissue. Explants were incubated for 24 hours under standard cell culture conditions before conditioned media were collected for multiplex cytokine analysis and tissue was transferred to RNAlater (SigmaAldrich) for quantitative real-time RT-PCR or $4 \%$ paraformaldehyde for IHC analysis.

\section{IHC and Morphometric Analysis of Endometriosis-Like Lesions and Endometrial Explants}

Hematoxylin and eosin (Sigma-Aldrich) staining was performed on every 20th section from endometriosis-like lesions; one lesion from the control group was found not to contain glandular epithelium and was excluded from IHC analysis. The BrdU In-Situ Detection Kit (BD, North Ryde, NSW, Australia) was used to detect proliferating cells in endometriosis-like lesions as per the manufacturer's instructions. Mouse anti-human leukocyte antigen class 1 (HLA-1) (1:200 dilution; Abcam, Melbourne, VIC, Australia) was used for distinguishing human 
Table 1 Sequences and Concentrations of the Primers Used for Quantifying Cytokine mRNA Levels in Human Endometrial Explants in This Study

\begin{tabular}{|c|c|c|c|}
\hline Gene & Forward & Reverse & Concentration $(\mu \mathrm{mol} / \mathrm{L})$ \\
\hline CSF2 (GM-CSF) & $5^{\prime}-$ AGCCCTGGGAGCATGTGA-3' & 5'-CATCTCAGCAGTGTCTCTACTC-3' & 0.5 \\
\hline IL10 & 5'-GGGAGAACCTGAAGACCCTCA-3' & 5'-CCACGGCCTTGCTCTTGTT-3' & 0.25 \\
\hline CXCL1 (GRO $\alpha)$ & 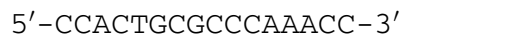 & 5'-GCAGGATTGAGGCAAGCTTT-3' & 0.5 \\
\hline CCL22 (MDC) & 5'-GCGCGTGGTGAAACACTTC-3' & $5^{\prime}$-ACTCTGGGATCGGCACAGAT-3' & 0.25 \\
\hline$I L 1 B$ & $5^{\prime}-\mathrm{CCTGAGCTCGCCAGTGAAA}-3^{\prime}$ & 5'-TTTAGGGCCTATCAGCTTCAAA-3' & 0.25 \\
\hline CCL4 (MIP-1 $\beta)$ & $5^{\prime}$-AGCGCTCTCAGCACCAATG-3' & $5^{\prime}$-CTTCCTCGCGGTGTAAGAAAA- 3' & 0.5 \\
\hline
\end{tabular}

Protein names that differ from the gene names are shown in parentheses.

GM-CSF, granulocyte macrophage colony-stimulating factor; GRO, growth-regulated oncogene; MDC, macrophage-derived chemokine; MIP, macrophage inflammatory protein.

and mouse tissue in xenografts. The antibody clone used (EMR8-5) recognizes a nonpolymorphic determinant present on all HLA-1 heavy chains (ie, A, B, and C). Additional sections were stained with rat anti-mouse F4/80 IgG2aк (1:800 dilution; eBioscience, San Diego, CA), mouse anti- $\alpha$-smooth muscle actin IgG2a (1:500; Sigma-Aldrich), or rabbit anti-von Willebrand factor polyclonal antibodies (1:600; Merck Millipore, Macquarie Park, NSW, Australia) to identify macrophages (murine), myofibroblasts, and endothelial cells, respectively. Sections from both endometriosis-like lesions and endometrial explants were stained with mouse anti-human CD68 (1:50 dilution; Dako, Campbellfield, VIC, Australia), mouse antiCD206 (1:200 dilution; R\&D Systems, Minneapolis, MN), rabbit anti-CCR7 (1:60,000 dilution; Abcam), and rabbit antiiNOS (1:1200 dilution; Santa Cruz Biotechnology, Dallas, TX) were used for identifying human macrophages and macrophages polarized to the M2 (CD206) or M1 (CCR7 and iNOS) phenotypes. Control sections were incubated with isotypematched control antibody at the same dilution or Flex universal mouse negative control (Dako).

Briefly, slides were dewaxed and rehydrated in a descending ethanol series. Antigen retrieval was performed in $\mathrm{pH} 6.0$ sodium citrate buffer $(10 \mathrm{mmol} / \mathrm{L}$ each citric acid and tri-sodium citrate) for 5 to 20 minutes, except for CD68 and CD206, which were performed in $\mathrm{pH} 9.0$ Tris-EDTA buffer (10 mmol/L Tris, $1 \mathrm{mmol} / \mathrm{L}$ EDTA) for 5 minutes. Slides were allowed to cool for 20 minutes, washed thrice with phosphate-buffered saline, and quenched with $3 \%$ hydrogen peroxide (Sigma-Aldrich) before being incubated with $10 \%$ serum (from the species of origin of the secondary antibody) in phosphate-buffered saline with or without $1 \%$ bovine serum albumin. Sections were then incubated with the primary antibodies in phosphate-buffered saline with $2 \%$ to $10 \%$ serum overnight at $4^{\circ} \mathrm{C}$. After washing, biotinylated secondary antibodies were applied for 30 to 60 minutes and detected using streptavidin-horseradish peroxidase (1:500; Dako), both at room temperature. Diaminobenzidine (Dako) was used for visualizing the stain. Slides were counterstained with hematoxylin, dehydrated, and mounted, and coverslips were applied.

Morphometric analyses were performed by an assessor (J.Z. or J.T.M.) blinded to treatment group. Sections were imaged using a NanoZoomer (Hamamatsu Photonics, Hamamatsu, Japan). The proportion of BrdU-positive cells was calculated by manual counting in ImageJ software version $1.48(\mathrm{NIH}$, Bethesda, MD) of at least 1300 cells in at least three fields per lesion. HLA-1-positive and macrophage-free stromal area was determined by measuring the glands (epithelium and lumen) and the subepithelial portion of stroma containing/devoid of substantial staining, respectively, and expressed as a percentage of the total area of each section (NanoZoomer Viewer, Hamamatsu Photonics). F4/80, von Willebrand factor, and $\alpha$-smooth muscle actin staining in endometriosis-like lesions was analyzed in up to 10 fields using VideoPro 32 software version 2.1 (Leading Edge, Adelaide, SA, Australia) and expressed as percentage of positive area. CD68, CD206, CCR7, and iNOS were similarly measured in multiple fields encompassing the entire endometrial explant tissue section.

\section{Multiplex Cytokine Analysis of Conditioned Media}

A custom Milliplex MAP Human Cytokine/Chemokine 96-well multiplex assay (Merck Millipore) was designed and run on a Luminex 200 System (Luminex Corp., Austin, $\mathrm{TX}$ ) according to the manufacturer's instructions. The minimal detectable limits of the 20 analytes ranged from 0.4 to $26.3 \mathrm{pg} / \mathrm{mL}$. A separate assay (R\&D Systems) was used for assessing IL-4 and macrophage CSF levels in conditioned media. Samples that were below the minimal detectable limits were excluded; only analytes for which $>50 \%$ of samples tested were above the minimal detectable limits were considered for statistical analysis. The mean intra- and interassay coefficients of variation for each analyte were $13 \%$ and $5 \%$, respectively.

\section{Quantitative Real-Time RT-PCR Analysis of Seminal Plasma-Treated Explants}

Total RNA was extracted from seminal plasma-treated and control explants using TRIzol reagent (Life Technologies) with RNeasy column purification (Qiagen, Chadstone, VIC, Australia) as per the manufacturer's instructions. Spectrophotometric analysis on a NanoDrop ND-1000 (Thermo Scientific) confirmed the purity of the resultant sample 
A

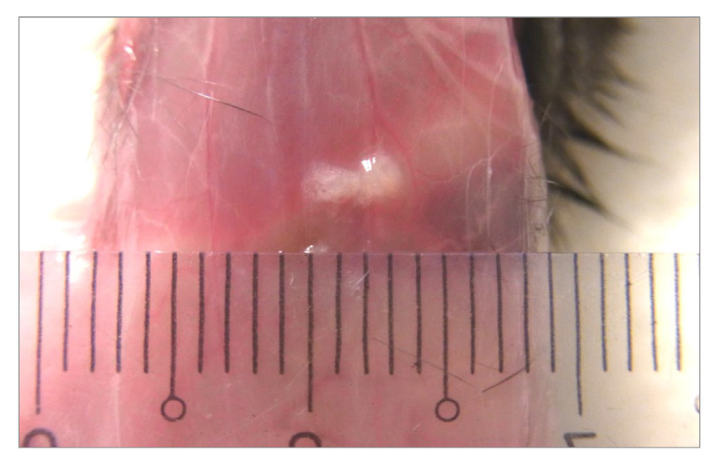

B

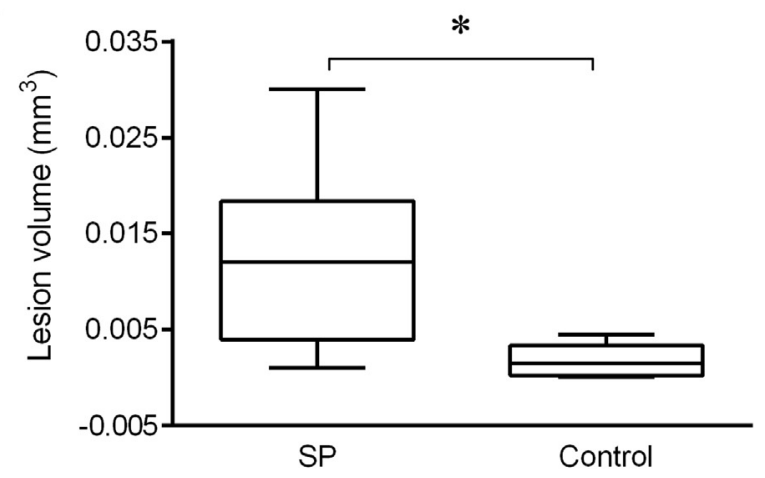

C

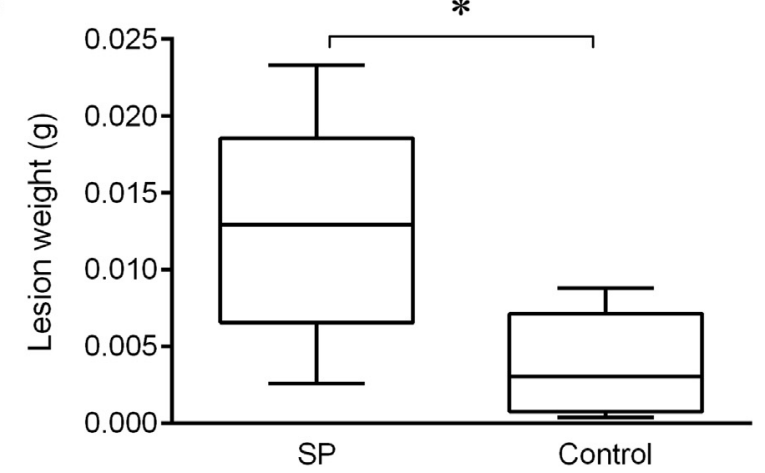

Figure 1 Effect of exposure to seminal plasma on endometriosis-like lesion development in mice. A: A representative mouse with tissue; endometriosis-like lesions are visible in the s.c. space 14 days after transfer. B and C: The volume (B) and weight (C) of endometriosis-like lesions recovered from mice that received seminal plasma (SP)-treated endometrial tissue or human endometrial tissue incubated in media alone (control). The boxes represent the medians and interquartile ranges; whiskers represent minimal and maximal values. $n=6$ per group. ${ }^{*} P<0.05$ (U-test).

[A260:A280, $1.9 \pm 0.1$ (means \pm SEM)]. Total RNA (60 ng) was reverse-transcribed in a volume of $20 \mu \mathrm{L}$ using SuperScript III with $250 \mathrm{ng}$ random primers (both, Life Technologies) as per the manufacturer's instructions. PCR was performed in triplicate for $A C T B$ and in duplicate for cytokine genes using Power SYBR Green Master Mix on an Applied Biosystems 7900HT Real-Time PCR system (both, Life Technologies). Cytokine gene fold-change in response to treatment with seminal plasma was calculated using the
${ }^{\Delta \Delta} \mathrm{Ct}$ method. The primer sequences used are listed in Table 1. Primer concentration was optimized in pilot studies, and dissociation curve analysis confirmed the absence of dimer formation for each pair. $\mathrm{Ct}$ values for the endogenous control gene did not differ significantly between the groups [control, $24.1 \pm 1.0 ; 10 \%$ seminal plasma, $25.0 \pm 1.9$ (means \pm SEM)]. The coefficient of variation for replicate PCR wells was $1.25 \% \pm 0.4 \%$ (means \pm SEM of cytokine genes).

\section{Statistical Analysis}

All analyses of endometriosis-like lesions and endometrial explants were performed using the $U$-test or Wilcoxon signed rank test for independent or related samples, respectively, as appropriate. For in vivo data, analyses were performed on values for individual mice. Cytokine concentration in conditioned media from human endometrial explants was analyzed by 1-way analysis of variance and Fisher's least significant difference post hoc tests after passing the ShapiroWilk test for normality. Fold-change cytokine mRNA levels were analyzed by 1 -sample $t$-test. Correlation between morphometric variables was assessed using the Pearson coefficient. The software programs used were GraphPad Prism version 5.01 (GraphPad Software, San Diego, CA), SAS version 9.3 (SAS Institute, Cary, NC), and SPSS Statistics version 20 (IBM, Armonk, NY).

\section{Results}

\section{Seminal Plasma Exposure Enhances the Size and Weight of Endometriosis-Like Lesions}

Initially, to test the effect of seminal plasma on the development of endometriosis-like lesion, we used the SCID mouse model of endometriosis and exposed tissues to human seminal plasma before transfer to recipient mice. On day 14 after transfer, SCID mouse xenografts originating from seminal plasma-exposed endometrium were found to be significantly larger $(P=0.015)$ and heavier $(P=0.026)$ than lesions originating from tissue exposed to culture medium alone (Figure 1, B and C). There was no significant effect of treatment on the proportion of mice that developed endometriosislike lesions (6 of 10 mice in the seminal plasma exposure group and 6 of 11 control mice).

\section{Seminal Plasma Expands the Donor Tissue} Compartment and Promotes Epithelial Proliferation in Endometriosis-Like Lesions

Hematoxylin and eosin analysis did not reveal any difference in the fractional area of glands or stroma in endometriosislike lesions exposed to seminal plasma $(P=0.309)$. However, lesions may contain both donor human and host mouse tissue, and hematoxylin and eosin staining does not distinguish between these. We thus examined the relative 


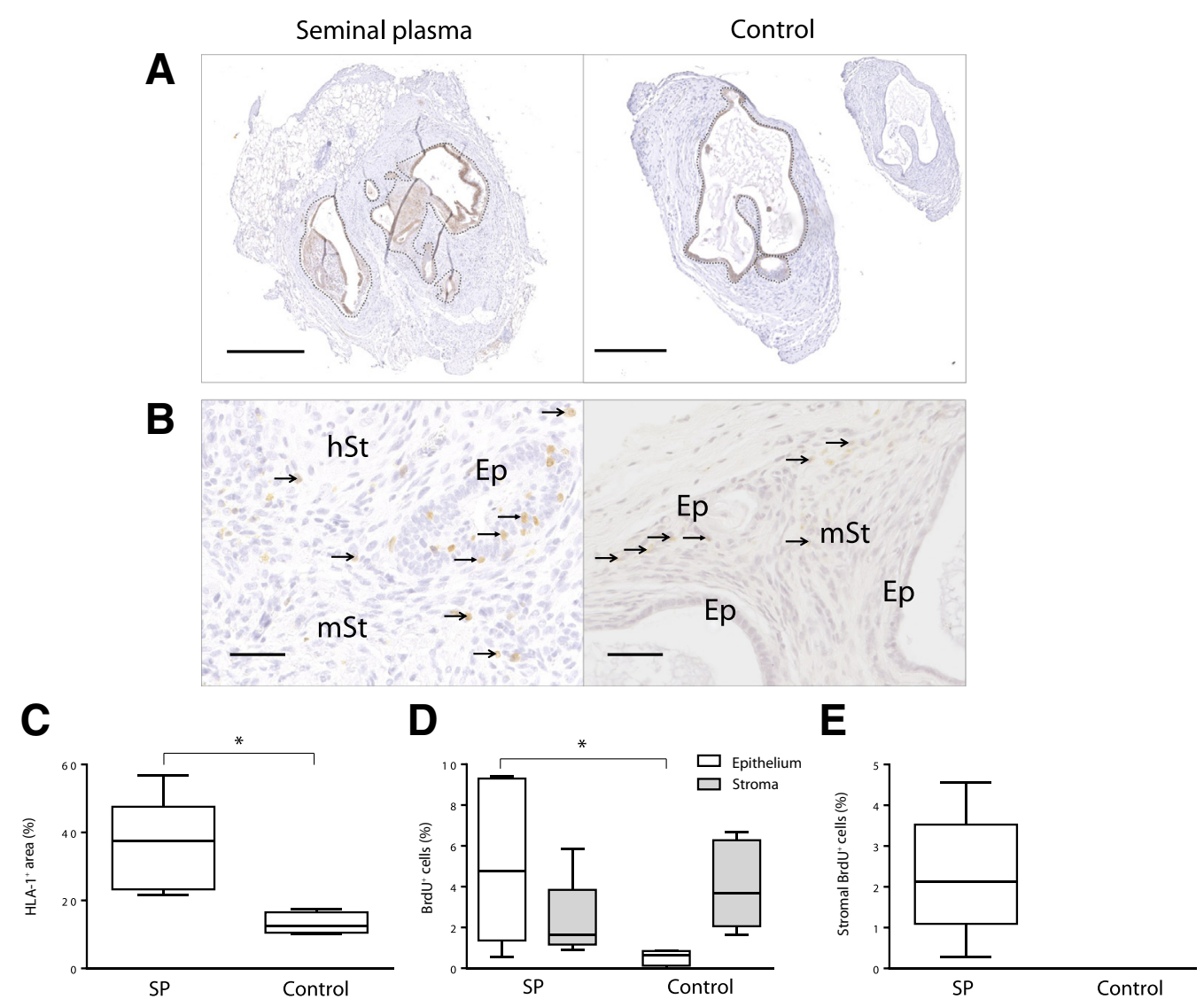

Figure 2 Effects of exposure to seminal plasma on tissue composition and cellular proliferation of endometriosis-like lesions. Representative sections (A) and quantitative analysis (C) of tissue area immunopositive for human leukocyte antigen class 1 (HLA-1) from seminal plasma-treated and control groups. Dotted lines delineate HLA-1-positive $\left(\mathrm{HLA}-1^{+}\right)$tissue boundaries. Inset: Isotype-matched antibody negative control. B: Representative images of seminal plasma (SP)-treated and control lesions stained for 5-bromo-2'-deoxyuridine (BrdU). Large and small arrows mark BrdU ${ }^{+}$stromal and epithelial cells, respectively. $\mathbf{D}$ and $\mathbf{E}: \mathrm{BrdU}^{+}$cells were quantified and expressed as the percentages of the total number of cells in the epithelium and in the entire stroma (ie, combined human and murine) (D) and in the human stromal tissue compartment alone (E). The boxes represent the medians and interquartile ranges; whiskers represent minimal and maximal values. $n=6$ and 4 mice in the SP and control groups, respectively, because in one control lesion, glandular material was insufficient for quantification. ${ }^{*} P<0.05$ (U-test). Scale bars: $500 \mu \mathrm{m}$ (seminal plasma) or $250 \mu \mathrm{m}$ (control) (B); $50 \mu \mathrm{m}$ (C). Ep, glandular epithelium; hSt, human stroma; mSt, murine stroma.

proportion of human and murine tissue in lesions using an antibody to HLA-1, which is exclusively expressed by human cells. There was a significantly greater proportion of donor tissue in endometriosis-like lesions from the seminal plasma group $(P=0.016)$ (Figure 2, A and C). Large areas of human stromal tissue were identified surrounding the human-derived glandular epithelium in lesions that had been exposed to seminal plasma. In contrast, human stromal tissue was rarely detected in control lesions, and only the glandular epithelium expressed HLA-1.

We hypothesized that enhanced cellular proliferation in the human tissue compartment may have accounted for this increased tissue area. When proliferating cells were quantified, BrdU-positive epithelial cells were significantly more numerous in endometriosis-like lesions after seminal plasma treatment compared with controls $(P=0.038)$ (Figure 2, B and $\mathrm{D})$. There was no difference between the groups in the number of BrdU-positive cells in the stroma when mouse and human tissue were considered as a whole. Substantial proliferation was also observed in the human stromal tissue of the lesions exposed to seminal plasma, but since this compartment was effectively absent from control lesions, no stromal cell proliferation was detected in those tissues (Figure 2E). Within seminal plasma-treated lesions, the concentration of proliferating cells was significantly greater in the human compared with the murine stromal tissue compartment $(P=0.046)$ (Supplemental Figure S1).

\section{Seminal Plasma Alters Macrophage Distribution in Endometriosis-Like Lesions}

Measurement of F4/80 staining revealed no difference in the density of mouse macrophages in lesions from the two groups. However, the spatial distribution was altered in lesions exposed to seminal plasma such that there was a larger area of stromal tissue subjacent to the epithelium where host mouse macrophages failed to infiltrate (Figure 3A). In contrast, macrophages were observed in close proximity to the glandular epithelium in lesions from the control group (Figure 3A). The difference in the 

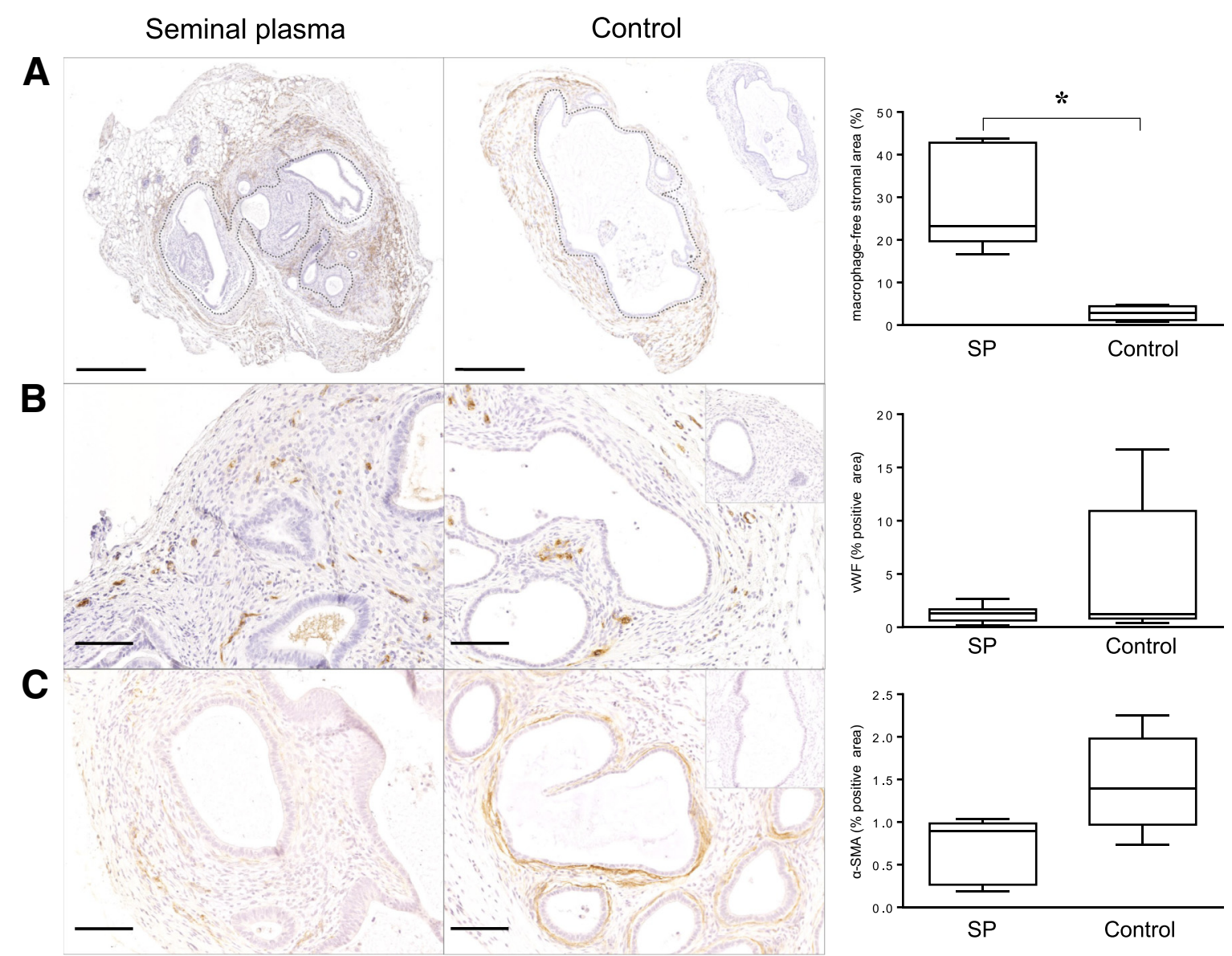

Figure 3 Effects of exposure to seminal plasma on mouse macrophage distribution and endothelial cell and fibroblast density in endometriosis-like lesions. Representative images of sections from seminal plasma (SP)-treated (left) and control tissues (center) stained for F4/80 (A), von Willebrand factor (vWF) (B), and $\alpha$-smooth muscle actin ( $\alpha$-SMA) (C). Dotted lines (A) delineate F4/80-positive (F4/80 $)$ tissue boundaries. Insets, B and C: Isotype-matched antibody negative controls. The proportions of subepithelial stromal tissue principally devoid of macrophages (graphs, $\mathbf{A}$ ) and the percentage of area of tissue stained for vWF (graphs, B) or $\alpha$-SMA (graphs, C). Boxes represent the medians and interquartile ranges; whiskers represent minimal and maximal values. $n=6$ and 4 mice in the SP and control groups, respectively, because in one control lesion glandular material was insufficient for quantification. ${ }^{*} P<0.05$ ( $U$-test). Scale bars: $500 \mu \mathrm{m}$ (seminal plasma) or $250 \mu \mathrm{m}$ (control) (A); $100 \mu \mathrm{m}$ (B and C).

proportion of macrophage-free stroma was statistically significant $(P=0.016)$, with a pattern of distribution inverse to that of HLA-1. There was a significant correlation between macrophage-free stromal and HLA-1-positive area $(r=0.91 ; P=0.00006)$. Tissue controls confirmed that the F4/80 antibody used is specific to mouse macrophages and does not react with human endometrium, whereas HLA-1 was detected in human endometrium but not in murine tissues (Supplemental Figure S2).

Analysis of von Willebrand factor staining indicated no difference in blood vessel density after exposure to seminal plasma (Figure 3B). Like mouse macrophages, myofibroblasts were routinely observed subjacent to the epithelial layer in control lesions, but myofibroblasts in this location were rare in seminal plasma-exposed lesions (Figure 3C). There was a trend toward reduced myofibroblast density, as measured by $\alpha$-smooth muscle actin staining in seminal plasma-exposed lesions $(P=0.056)$. There were no differences in von Willebrand factor or $\alpha$-smooth muscle actin staining between the human and mouse compartments of seminal plasmaexposed lesions.

\section{Seminal Plasma Does Not Change Macrophage Phenotype or Number in Endometriosis-Like Lesions or Explants}

As the distribution of mouse macrophages was altered in seminal plasma-exposed endometriosis-like lesions, we sought to characterize the macrophages present. Using the human macrophage marker CD68, we observed that in contrast to naïve endometrial tissue (which is replete with macrophages), endometriosis-like lesions from both the seminal plasma-treated and control groups contained only sporadic CD68-positive cells (Figure 4A).

To determine whether macrophages displaying markers of alternate (M2) or acute (M1) activation were present in endometriosis-like lesions, IHC qualification of MMR/ CD206, CCR7, and iNOS was undertaken. MMR-positive cells (M2 macrophages) displayed a similar pattern to that of 


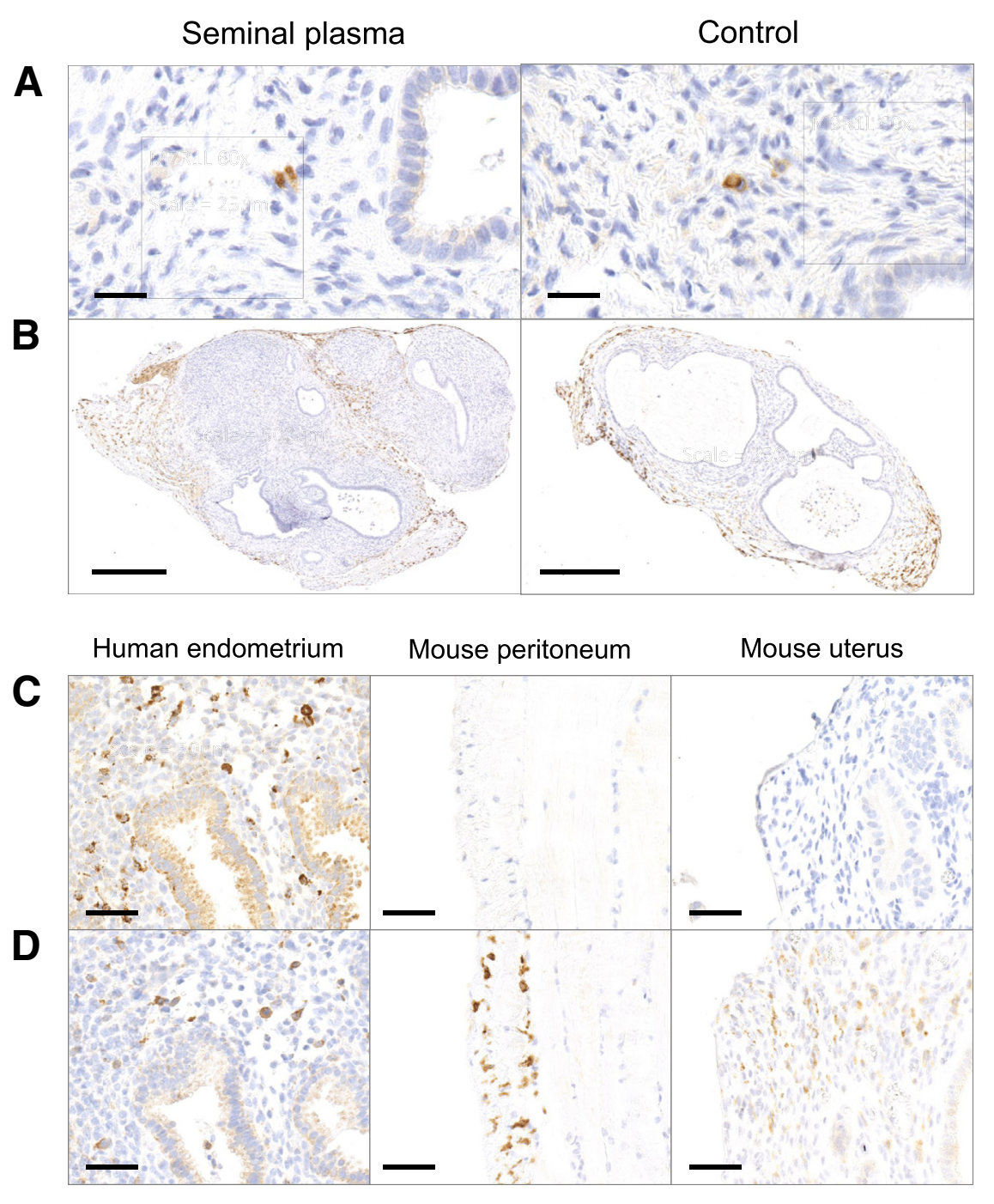

Figure 4 Effects of exposure to seminal plasma on human macrophages and macrophage phenotype in endometriosis-like lesions. Representative images from seminal plasma-treated sections and control-group sections stained for CD68 (A) and macrophage mannose receptor (MMR/CD206) (B). Tissue controls demonstrated the specificity of the CD68 (C) and MMR antibodies (D). Scale bars: 25 $\mu \mathrm{m}$ (A); $500 \mu \mathrm{m}$ (seminal plasma) or $250 \mu \mathrm{m}$ (control) (B); $50 \mu \mathrm{m}$ (C and D).

F4/80 staining and were detected in the murine but not in the human compartment of endometriosis-like lesions (Figure 4B). There was no difference in MMR-positive macrophage density between the groups. Tissue controls confirmed that the CD68 antibody detects only human macrophages (Figure 4C), whereas the MMR antibody detects M2 macrophages of both human and mouse origin (Figure 4D). There were few or no CCR7- or iNOS-positive cells (M1 macrophages) in either seminal plasma-treated or control lesions.

To evaluate whether seminal plasma exposure skewed markers of macrophage activation earlier in the time course of lesion development, endometrial explants were examined immediately after exposure to seminal plasma in vitro. Macrophages as defined by CD68 immunoreactivity were abundant in seminal plasma-treated and control tissue after 24 hours in culture (Figure 5A). As in endometriosis-like lesions, M2 (MMR-positive) macrophages were readily detected (Figure 5B), whereas endometrial explants were relatively devoid of M1 (CCR7-/iNOS-positive) macrophages (Figure 5, C and D). Seminal plasma did not alter the density of CD68-, MMR-, CCR7-, or iNOS-positive cells
(Figure 5E). Breast cancer control sections confirmed that CCR7 and iNOS proteins were detectable with the IHC procedure used (Supplemental Figure S3).

\section{Seminal Plasma Modulates Cytokine Profile in Human Endometrial Explants}

To investigate the mechanism by which seminal plasma exerts biological effects in endometrial tissue, cytokine production and mRNA expression were evaluated in response to seminal plasma exposure. In vitro treatment with $10 \%$ seminal plasma for 24 hours resulted in significantly higher concentrations of macrophage inflammatory protein $1 \beta$, GM-CSF, IL-1 $\beta$, macrophage-derived chemokine, IL-10, and growth-regulated oncogene (GRO) in conditioned media of tissues treated with seminal plasma compared with those in seminal plasma alone or tissue alone (all, $P<0.05$ by 1 -way analysis of variance) (Figure 6A), and a seminal plasma-induced increase in IL-8 was of borderline significance $(P=0.051)$ (Supplemental Figure S4). Levels of macrophage CSF, granulocyte CSF, IL-1 $\alpha$, IL-6, interferon $\gamma$-inducible protein 10 , monocyte 


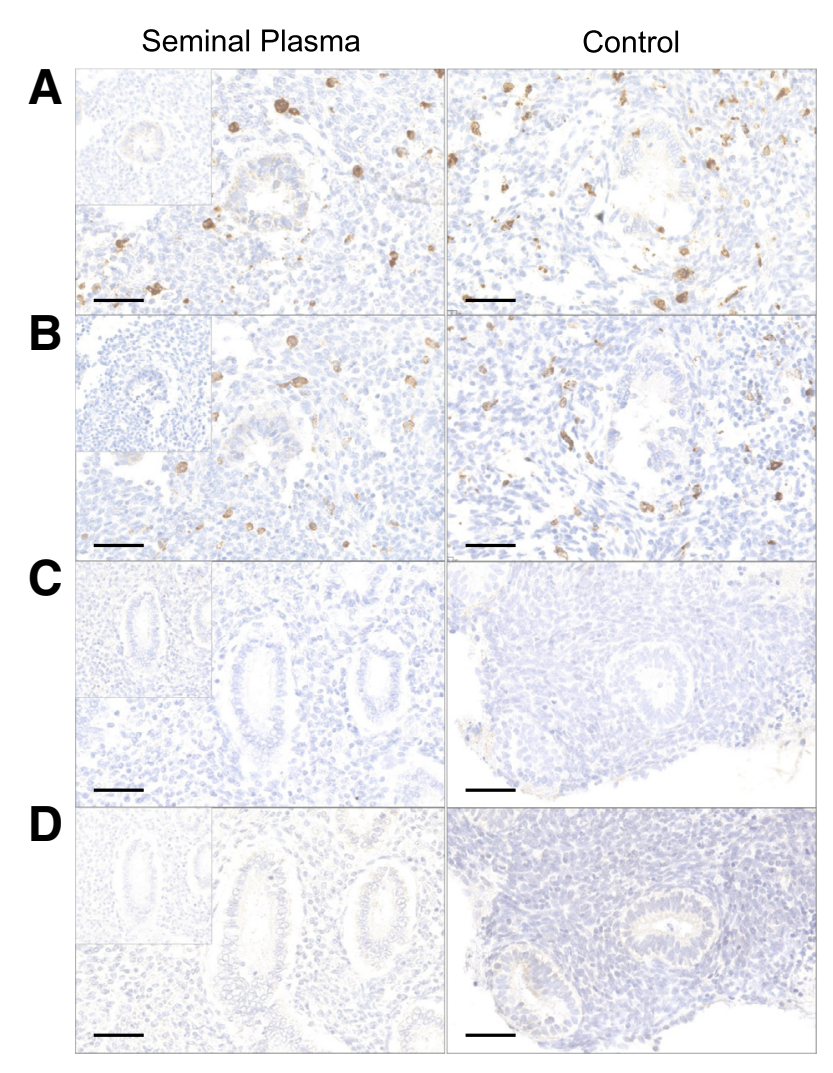

E

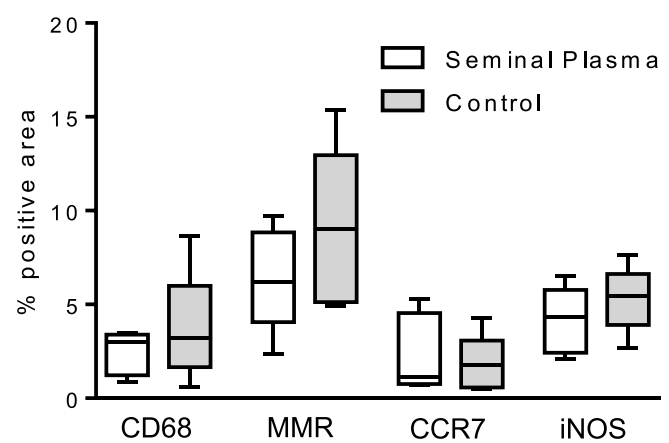

Figure 5 Effects of seminal plasma on macrophage abundance and phenotype in human endometrial explants. Tissues were treated with seminal plasma or control medium for 24 hours in triplicate and processed for immunohistochemistry analysis. Representative images of sections stained for CD68 (A), macrophage mannose receptor (MMR/CD206) (B), classic chemokine receptor (CCR)-7 (C), and nitric oxide (iNOS) (D). Insets: Isotype-matched antibody negative controls. E: The percentages of area of tissue stained for each antigen are quantified. The boxes represent the medians and interquartile ranges; whiskers represent minimal and maximal values (no significant differences were found). Data were compared by $U$-test. $n=5$. Scale bar $=50 \mu \mathrm{m}$.

chemotactic proteins 1 and 3 , regulated on activation normal $\mathrm{T}$ cell expressed and secreted, tumor necrosis factor $\alpha$, and vascular endothelal growth factor A were not different between the treatment groups, although tissue incubated with seminal plasma produced the numerically highest concentration in each case (Supplemental Figure S4). IL-4, eotaxin, fractalkine, IL-1RA, and macrophage inflammatory protein $1 \alpha$ were undetectable in $\geq 50 \%$ of the explants tested.
At the mRNA level, there was a trend toward increased transcript abundance for each of the cytokines that were elevated in conditioned media after seminal plasma exposure (Figure 6B). This finding was most pronounced for IL$1 \beta$ (fold-change, $4.43 \pm 1.86$ ). Statistical significance was not reached, partly due to considerable patient-to-patient variability.

\section{Discussion}

This is the first study to demonstrate an association between contact with seminal plasma and the development of endometriosis in an in vivo model. Direct endometrial exposure to seminal plasma was associated with consistent and substantial increases in the volume and weight of resultant endometriosislike lesions. Morphometric analysis of the lesions demonstrated an increased proportion of tissue immunopositive for HLA-1, a substantial impact on the persistence of the human endometrial stromal compartment, and increased endometrial epithelial cell proliferation. These findings indicate an increased propensity of human endometrial tissue to survive and proliferate at an ectopic site after contact with seminal plasma.

Few macrophages were seen in the large areas of retained human stroma surrounding the glands in seminal plasmaexposed lesions. Moreover, differences in total macrophage density or macrophage activation status were not detected in xenografts or in human endometrial tissue explants exposed to seminal plasma in vitro. Thus the endometrial cytokine response to seminal plasma appears predominantly to directly support the proliferation of epithelial cells and the survival of stromal cells of endometrial origin, rather than the induction of alterations in macrophage activity and function to promote endometriosis-like lesion development.

\section{Rationale and Study Limitations}

The SCID mouse model of endometriosis used in this study offers the advantage of in vivo functional assessment of human endometrial tissues, which is not possible in syngeneic mouse models or in clinical trials in women. Although macrophage activity and innate immune responses are intact in SCID mice, humoral T- and B-cell activity is absent, which is a limitation in its representation of human disease. Although our findings suggest that retrograde-shed endometrium exposed to seminal plasma in vivo could have a higher propensity for proliferation and growth at an ectopic site in women, additional clinical studies are required for validation of this theory. There is some epidemiological evidence to support this premise, as endometriosis is more common in women who report coitus during menses compared with patients who avoid intercourse at that time. ${ }^{31}$

Postcoitally, the cervix encounters seminal plasma at moderate to high concentrations; however, the extent to which seminal plasma contacts the endometrium after intercourse is difficult to measure in women and remains a point of contention. Uterine insuck of seminal fluid has been proposed as a 

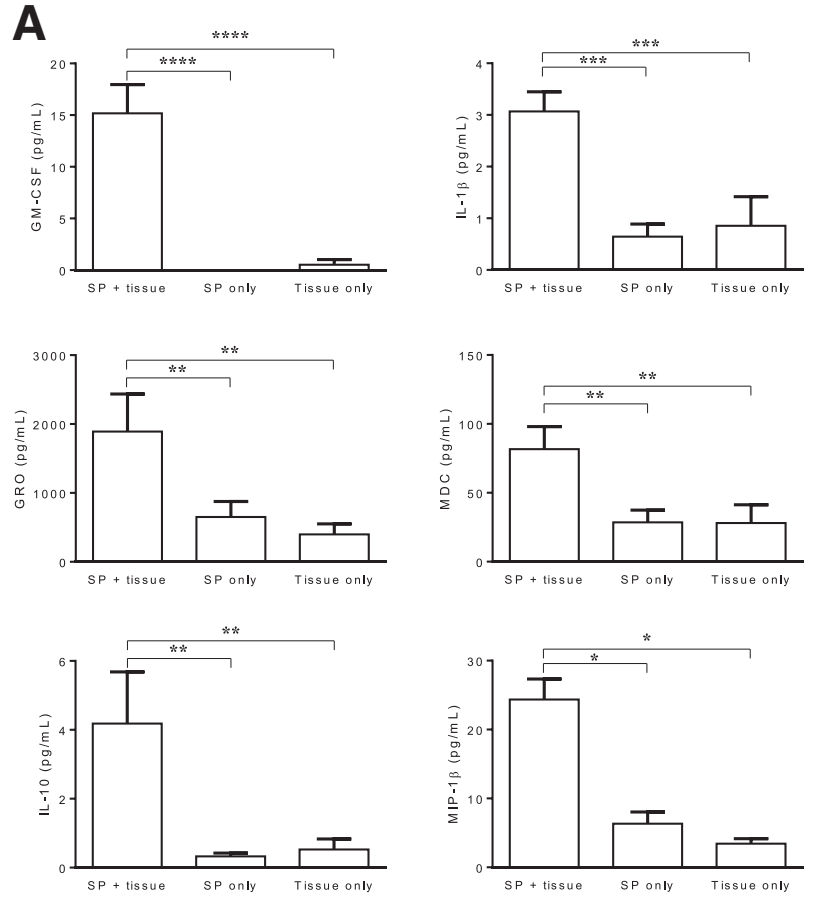

B

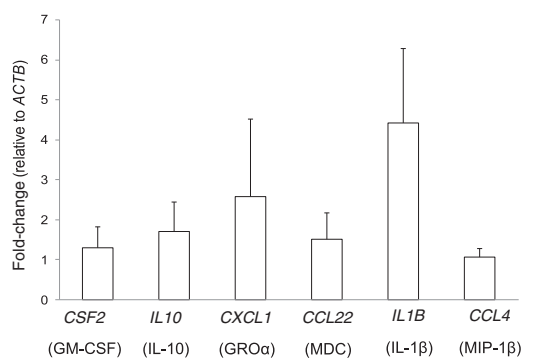

Figure 6 Effects of seminal plasma on synthesis of macrophage inflammatory protein (MIP)-1 $\beta$, granulocyte macrophage colony-stimulating factor (GM-CSF), IL-1 $\beta$, macrophage-derived chemokine (MDC), IL-10, and growthregulated oncogene (GRO) by human endometrial explants. Tissues were treated with seminal plasma (SP + tissue) or control medium (tissue only) for 24 hours in triplicate. Additional control wells contained media with $10 \%$ seminal plasma but no tissue (SP only). Conditioned media were collected for Luminex multiplex analysis (Luminex Corp., Austin, TX) (A), and tissue was transferred to RNA later for subsequent total RNA extraction and quantitative real-time RT-PCR analysis (B). Minimal detectable limits $(\mathrm{pg} / \mathrm{mL})$ for cytokine assays: MIP-1 $\beta, 4.5$; GM-CSF, 9.5; IL-1 $\beta, 0.4 ;$ MDC, 3.7; IL-10, 0.3; and GRO, 10.1. Protein data are means \pm SEM and were compared by 1 -way analysis of variance with least significant difference post hoc testing; gene-expression data were normalized to ACTB (encoding $\beta$-actin, as endogenous control gene) expression and are expressed as means fold-change \pm SEM relative to control tissue (no significant differences were found). $n=3$ to 4 samples per group. ${ }^{*} P<0.05,{ }^{* *} P<0.01,{ }^{* * *} P<0.001$, and ${ }^{* * * *} P<0.0005$.

physiological possibility, ${ }^{32-34}$ and several studies have demonstrated that technetium-labeled albumin macrospheres placed at the external os of the cervix reach the tubes within 1 minute as a result of subendometrial and myometrial peristaltic activity. ${ }^{35,36}$ Uterine contraction induced by menstruation ${ }^{34}$ and coitus may increase vagina-to-uterus transport, thus exposing intact and shedding endometrium to higher seminal plasma concentrations and could enhance retrograde flow of endometrial debris into the peritoneal cavity. Other mechanisms, including binding of TGF- $\beta$ and other active seminal constituents to the postacrosomal region of the sperm head ${ }^{37}$ provide further support for the concept of a physiologically relevant interaction between endometrium and seminal plasma constituents.

\section{Direct Effect of Seminal Plasma on Endometrial Tissue}

Increased proliferation of endometrial epithelial cells was seen in xenografts derived from endometrial tissue exposed to seminal plasma. Enhanced proliferation after exposure to seminal plasma was previously demonstrated in endometrial epithelial cell cultures and in a xenograft model of endometrial adenocarcinoma, ${ }^{16-18}$ consistent with our findings. Here, persistence of human donor stromal cells was identified only in endometriosis-like lesions exposed to seminal plasma, suggesting that direct exposure induces survival and proliferation of the both the stromal and the epithelial compartments of human endometrium. The surrounding murine stromal tissues did not demonstrate differences in cellular proliferation. This finding indicates that seminal plasma-induced changes in the tissue exert a predominantly local effect on human endometrial cells. Although we did not detect any changes in mouse macrophages or other overt aspects of the host compartment that would suggest an indirect effect of seminal plasma, we cannot exclude effects in host immune or other cells.

\section{Lack of Host Macrophage, Myofibroblast, and Vascular Cell Response}

Cytokines produced by endometrial tissue in response to seminal plasma are likely to induce recruitment and activation of immune cells, ${ }^{23,24}$ which could in turn contribute to the establishment and/or growth of xenografts. However, the numbers of macrophages and myofibroblasts in endometriosis-like lesions were not altered by seminal plasma exposure. This finding was unexpected, as lower numbers of both cell types were identified in association with smaller lesions in the host TGF$\beta 1-$ deficient mouse model of endometriosis, ${ }^{14}$ and seminal plasma is an abundant source of TGF- $\beta 1$ that induces profound leukocyte recruitment in the female reproductive tract after coitus. ${ }^{24,38}$ This difference between the effect of seminal plasma and TGF- $\beta 1$ manipulation could relate to the presence of other bioactive moieties in seminal plasma, including prostaglandin $\mathrm{E}$ or various steroid hormones (eg, estrogen). ${ }^{39,40}$

In xenografts exposed to seminal plasma, the distribution of macrophages was altered, with few macrophages (human or murine) in the abundant human endometrial stromal tissue surrounding endometrial glandular epithelial cells. We explored the macrophage activation status in xenografts and in tissue explants exposed to seminal plasma in vitro. In both experiments, the M2 macrophage marker MMR was relatively prevalent, but seminal plasma exposure did not appear to alter its expression. The M1 markers iNOS and CCR7 demonstrated very low abundance, providing evidence that in endometrial explants in vitro and in endometriosis-like 
Table 2 Cytokines Induced in Endometrial Tissue in Response to Seminal Plasma

\begin{tabular}{|c|c|c|c|}
\hline Cytokine & Immune/reproductive function & Effect in endometriosis models & Regulation in endometriosis \\
\hline GM-CSF & $\begin{array}{l}\text { Pro-inflammatory } \\
\text { Postcoital leukocyte recruitment } \\
\quad \text { and activation (esp. DC) (reviewed }{ }^{51-53} \text { ) }\end{array}$ & Unknown & $\begin{array}{l}\leftrightarrow \text { In peritoneal fluid }{ }^{54,55} \\
\leftrightarrow \text { In peripheral blood } \\
56,57\end{array}$ \\
\hline GRO & $\begin{array}{l}\text { Pro-inflammatory/angiogenic/tumorigenic } \\
\text { Neutrophil chemotaxis } \\
\uparrow \text { Survival and malignant } \\
\text { transformation (ovarian EC) } \\
\uparrow \text { Endothelial cell tube formation } \\
60\end{array}$ & Unknown & $\uparrow$ In peritoneal fluid $^{30,61}$ \\
\hline $\mathrm{IL}-1 \beta$ & $\begin{array}{l}\text { Pro-inflammatory } \\
\uparrow \text { Master Th2 cytokine TSLP (thymic } \\
\text { stromal lymphoprotein) (pHESC) } \\
\downarrow \text { Apoptosis (pHEEC) } \\
\uparrow \text { Cytokines (eg, GR0, GM-CSF, IL-8, } \\
\text { and IL-1 } \beta \text { ) (pHESC; mRNA) }\end{array}$ & $\begin{array}{l}\uparrow \text { Angiogenic/pro-inflammatory } \\
\text { factors (ie, VEGF/IL-6) (pHEcSC; mRNA } \\
\text { and protein) } \\
\downarrow \text { Inhibitory mediator of cell cycle } \\
\text { progression (Tob-1) (pHEcSC) } \\
\uparrow \text { Migration/invasion (EcMSC) }\end{array}$ & $\uparrow^{63,64}$ or $\leftrightarrow{ }^{65}$ In peritoneal fluid \\
\hline MIP-1 $\beta$ & $\begin{array}{l}\text { NK cell chemotaxis } \\
\downarrow \text { In endometritis (endometrium) } \\
\uparrow \text { During labor (choriodecidua; } \\
\text { mRNA and protein) }\end{array}$ & Unknown & $\begin{array}{l}\uparrow \text { In ovarian and peritoneal } \\
\text { lesions at the mRNA level }\end{array}$ \\
\hline IL-10 & $\begin{array}{l}\text { Anti-inflammatory } \\
\downarrow \text { Macrophage activation } \\
\quad(\text { ie, MHC Class II) } \\
\uparrow \text { Tolerogenic macrophages } \\
\quad \text { (mouse decidua) }^{79}\end{array}$ & $\begin{array}{l}\downarrow \text { TNF- } \alpha \text {-induced inflammatory } \\
\text { pathways in } \mathrm{pHECSC}^{80}\end{array}$ & $\uparrow^{81}$ or $\leftrightarrow^{82}$ In peritoneal fluid \\
\hline
\end{tabular}

DC, dendritic cell; EC, epithelial cell; EcMSC, ectopic mesenchymal stem cell; GRO, growth-regulated oncogene; MDC, macrophage-derived chemokine; MHC, major histocompatibility complex; MIP, macrophage inflammatory protein; ND, not detectable; NK, natural killer; pHEcSC, primary human ectopic stromal cell; PHEEC, primary human endometrial epithelial cell; pHESC, primary human endometrial stromal cell; TNF, tumor necrosis factor; Tob-1, transducer of erbB2.1; VEGF, vascular endothelial growth factor.

xenografts, the reparative environment associated with alternate M2 macrophage activity prevails. This environment was previously shown to enhance ectopic endometrial lesion development in a mouse model. ${ }^{22}$

We did not detect differences in blood vessel density between endometriosis-like lesions after seminal plasma exposure. A previous study attributed the enhanced development of s.c. HeLa tumor cell xenografts in response to seminal plasma to increased delivery of nutrients and oxygen via an enhanced vascular supply. ${ }^{16}$ Consistent with our result, there was no effect of seminal plasma on vascular epithelial growth factor production in vitro. The effects of seminal plasma in tumor cells and endometrial tissue may thus occur via different mechanisms.

\section{Cytokines Induced by Seminal Plasma Are Implicated in the Proliferative Effect}

Several of the cytokines up-regulated by seminal plasma in vitro promote cell proliferation and/or survival. For example, GRO $\alpha$ enhances proliferation in epithelial ovarian cancer cell lines, ${ }^{41}$ whereas IL-1 $\beta$ increases primary human endometrial stromal cell survival $^{42}$ and suppresses the expression of the cell cycle inhibitor transducer of erbB2.1 in ectopic endometriotic stromal cells. ${ }^{43}$ Both IL-1 $\beta$ and GM-CSF enhanced the proliferation of an epithelial gastric cancer cell line, ${ }^{44}$ although GM-CSF did not affect primary human endometrial epithelial or stromal cell proliferation. ${ }^{45}$ It is possible that there is interaction between growth factors induced in epithelial cells exposed to seminal plasma and the survival or proliferation of endometrial stromal cells, since growth factors secreted by endometrial epithelial cells are known to act in the stromal compartment. ${ }^{46}$

The cytokines we identified as secreted by endometrial explants are predicted to interact with several immune cell types, particularly of the myeloid lineage, with IL-1 $\beta$ and GRO being selectively secreted by monocytes and macrophage-derived chemokine by myeloid cells. $^{47}$

Increased endometrial explant production of GRO, GM$\mathrm{CSF}$, and IL-1 $\beta$ in response to seminal plasma is consistent 
with our previous findings in human cervix and ectocervical epithelial cells. ${ }^{23,24} \mathrm{We}$ found a trend to up-regulation of the mRNAs encoding these proteins, indicating that increased transcription is a mechanism of up-regulation likely to have at least partly contributed to our findings. Recently, Chen et $\mathrm{al}^{48}$ examined primary human endometrial stromal and epithelial endometrial cell responses to $1 \%$ seminal plasma for 6 hours. They found that seminal plasma significantly increased GRO and GM-CSF production in stromal and epithelial cells but that macrophage inflammatory protein $1 \beta$ was not affected. Endometrial explants contain immune cells, in contrast to endometrial and epithelial cell cultures, and the different secreted cytokine profiles are likely to reflect this difference.

Up-regulation of IL-1 $\beta$ in response to seminal plasma is consistent with findings in endometrial epithelial cell cultures. ${ }^{17}$ In a study by Lebovic et al, ${ }^{49}$ vascular epithelial growth factor and IL-6 mRNA and protein synthesis were enhanced by IL- $1 \beta$ in ectopic endometriotic but not eutopic endometrial stromal cells. IL-1 $\beta$ also induced the expression of $\mathrm{C}-\mathrm{X}-\mathrm{C}$ motif chemokine ligands 1,2 , and 8 and $\mathrm{CSF} 2^{50}$; $\mathrm{C}-\mathrm{X}-\mathrm{C}$ motif chemokine ligand 1 and CSF2 showed trends toward increased transcript abundance in our study. A feedforward IL-1 $\beta$ up-regulation of its own transcript was also identified. ${ }^{50}$ It is apparent that a complex network of cytokine and chemokine interactions occurs in endometrial tissues in response to seminal plasma that, as we have shown, is associated with a propensity for ectopic growth. Further work is required to tease out the relative contribution of the seminal plasma-induced cytokines to this process. The functions of the up-regulated cytokines and our current understanding of their roles in endometriosis are summarized in Table 2.

There was no significant induction of the major M2 macrophage polarizing cytokines IL-4 or macrophage CSF in endometrial explants exposed to seminal plasma, although seminal plasma itself contained significant quantities (approximately $3 \mathrm{ng} / \mathrm{mL}$ ) of macrophage CSF that may have influenced macrophage phenotype. To determine whether alterations in M1:M2 macrophage activity occurred early after seminal plasma exposure and were undetectable in day-14 lesions due to resolution of the inflammatory process in both experimental groups, the activation status of macrophages was examined in endometrial tissues after exposure to seminal plasma for 24 hours in vitro. Again, the M2 macrophage phenotype predominated in both groups, and there was no evidence that seminal plasma altered the activation status of macrophages. Therefore, this did not appear to have been the mechanism for the endometriosis-like lesion enhancement in response to seminal plasma exposure.

\section{Conclusion}

Seminal fluid and the postcoital inflammatory response it provokes in the reproductive tract contribute to optimal implantation and pregnancy outcomes. The current data provide proof of principle that seminal plasma can effect pathophysiological alterations in endometrial cells and tissues that, in the context of endometrial shedding during menses, may facilitate endometriotic lesion survival and development. The potential bioactive factor(s) in seminal plasma responsible for this effect include TGF- $\beta 1$, prostaglandin $\mathrm{E}$, and estradiol, ${ }^{39,40}$ but this remains to be determined. Women with pre-existing endometriosis may be particularly susceptible, as endometrial epithelial and stromal cells from women with endometriosis had an enhanced proliferative response to seminal plasma compared with that in cells from endometriosis-free women in vitro. ${ }^{18}$ It will be important to determine whether physiological routes of seminal plasma exposure do indeed confer an increased risk for endometriosis or contribute to its development in women. If so, modifications to sexual activity may reduce this risk and potentially lower the prevalence and severity of this disease.

\section{Acknowledgments}

We thank Suzanne Edwards for assistance with statistical analysis and Dr. Prabath Waagarachichi for endometrial tissue collection. We also acknowledge Dr. Wendy Ingman for assistance with CCR7, iNOS, and MMR IHC staining.

\section{Supplemental Data}

Supplemental material for this article can be found at http://dx.doi.org/10.1016/j.ajpath.2015.01.010.

\section{References}

1. Vinatier D, Orazi G, Cosson M, Dufour P: Theories of endometriosis. Eur J Obstet Gynecol Reprod Biol 2001, 96:21-34

2. Guo SW: Recurrence of endometriosis and its control. Hum Reprod Update 2009, 15:441-461

3. Somigliana E, Vigano P, Parazzini F, Stoppelli S, Giambattista E, Vercellini P: Association between endometriosis and cancer: a comprehensive review and a critical analysis of clinical and epidemiological evidence. Gynecol Oncol 2006, 101:331-341

4. Van Gorp T, Amant F, Neven P, Vergote I, Moerman P: Endome triosis and the development of malignant tumours of the pelvis. A review of literature. Best Pract Res Clin Obstet Gynaecol 2004, 18: 349-371

5. Nezhat F, Datta MS, Hanson V, Pejovic T, Nezhat C, Nezhat C: The relationship of endometriosis and ovarian malignancy: a review. Fertil Steril 2008, 90:1559-1570

6. Swiersz LM: Role of endometriosis in cancer and tumor development. Ann N Y Acad Sci 2002, 955:281-292; discussion 293-5, 396-406

7. Sinaii N, Cleary SD, Ballweg ML, Nieman LK, Stratton P: High rates of autoimmune and endocrine disorders, fibromyalgia, chronic fatigue syndrome and atopic diseases among women with endometriosis: a survey analysis. Hum Reprod 2002, 17:2715-2724

8. Gao X, Outley J, Botteman M, Spalding J, Simon JA, Pashos CL: Economic burden of endometriosis. Fertil Steril 2006, 86: $1561-1572$ 
9. Sampson JA: Peritoneal endometriosis due to menstrual dissemination of endometrial tissue into the peritoneal cavity. Am J Obstet Gynecol 1927, 14:442-446

10. Nyholt DR, Low SK, Anderson CA, Painter JN, Uno S, Morris AP, MacGregor S, Gordon SD, Henders AK, Martin NG, Attia J, Holliday EG, McEvoy M, Scott RJ, Kennedy SH, Treloar SA, Missmer SA, Adachi S, Tanaka K, Nakamura Y, Zondervan KT, Zembutsu H, Montgomery GW: Genome-wide association meta-analysis identifies new endometriosis risk loci. Nat Genet 2012, 44:1355-1359

11. Pizzo A, Salmeri FM, Ardita FV, Sofo V, Tripepi M, Marsico S: Behaviour of cytokine levels in serum and peritoneal fluid of women with endometriosis. Gynecol Obstet Invest 2002, 54:82-87

12. Loverro G, Maiorano E, Napoli A, Selvaggi L, Marra E, Perlino E: Transforming growth factor-beta 1 and insulin-like growth factor-1 expression in ovarian endometriotic cysts: a preliminary study. Int $\mathrm{J}$ Mol Med 2001, 7:423-429

13. Oosterlynck DJ, Meuleman C, Waer M, Koninckx PR: Transforming growth factor-beta activity is increased in peritoneal fluid from women with endometriosis. Obstet Gynecol 1994, 83:287-292

14. Hull ML, Johan MZ, Hodge WL, Robertson SA, Ingman WV: Hostderived TGFB 1 deficiency suppresses lesion development in a mouse model of endometriosis. Am J Pathol 2012, 180:880-887

15. Robertson SA, Ingman WV, O'Leary S, Sharkey DJ, Tremellen KP: Transforming growth factor beta-a mediator of immune deviation in seminal plasma. J Reprod Immunol 2002, 57:109-128

16. Sutherland JR, Sales KJ, Jabbour HN, Katz AA: Seminal plasma enhances cervical adenocarcinoma cell proliferation and tumour growth in vivo. PLoS One 2012, 7:e33848

17. Gutsche S, von Wolff M, Strowitzki T, Thaler CJ: Seminal plasma induces mRNA expression of IL-1 beta, IL-6 and LIF in endometrial epithelial cells in vitro. Mol Hum Reprod 2003, 9:785-791

18. Khan KN, Kitajima M, Hiraki K, Fujishita A, Sekine I, Ishimaru T, Masuzaki H: Effect of human seminal fluid on the growth of endometrial cells of women with endometriosis. Eur J Obstet Gynecol Reprod Biol 2010, 149:204-209

19. Bromfield JJ, Schjenken JE, Chin PY, Care AS, Jasper MJ, Robertson SA: Maternal tract factors contribute to paternal seminal fluid impact on metabolic phenotype in offspring. Proc Natl Acad Sci U S A 2014, 111:2200-2205

20. Capobianco A, Rovere-Querini P: Endometriosis, a disease of the macrophage. Front Immunol 2013, 4:9. doi:10.3389/fimmu.2013.00009

21. Gong D, Shi W, Yi SJ, Chen H, Groffen J, Heisterkamp N: TGFbeta signaling plays a critical role in promoting alternative macrophage activation. BMC Immunol 2012, 13:31. doi:10.1186/1471-2172-13-31

22. Bacci M, Capobianco A, Monno A, Cottone L, Di Puppo F, Camisa B, Mariani M, Brignole C, Ponzoni M, Ferrari S, PaninaBordignon P, Manfredi AA, Rovere-Querini P: Macrophages are alternatively activated in patients with endometriosis and required for growth and vascularization of lesions in a mouse model of disease. Am J Pathol 2009, 175:547-556

23. Sharkey DJ, Macpherson AM, Tremellen KP, Robertson SA: Seminal plasma differentially regulates inflammatory cytokine gene expression in human cervical and vaginal epithelial cells. Mol Hum Reprod 2007, 13:491-501

24. Sharkey DJ, Tremellen KP, Jasper MJ, Gemzell-Danielsson K, Robertson SA: Seminal fluid induces leukocyte recruitment and cytokine and chemokine mRNA expression in the human cervix after coitus. J Immunol 2012, 188:2445-2454

25. Robertson SA: Seminal fluid signaling in the female reproductive tract: lessons from rodents and pigs. J Anim Sci 2007, 85(13 Suppl): E36-E44

26. National Health and Medical Research Council: Australian Code of Practice for the Care and Use of Animals for Scientific Purposes. ed 8. Canberra, National Health and Medical Research Council, 2013

27. World Health Organization: WHO Laboratory Manual for the examination and processing of human semen. ed 5. Geneva, Switzerland, WHO Press, 2010
28. Bruner-Tran KL, Osteen KG, Taylor HS, Sokalska A, Haines K, Duleba AJ: Resveratrol inhibits development of experimental endometriosis in vivo and reduces endometrial stromal cell invasiveness in vitro. Biol Reprod 2011, 84:106-112

29. Herington JL, Crispens MA, Carvalho-Macedo AC, Camargos AF, Lebovic DI, Bruner-Tran KL, Osteen KG: Development and prevention of postsurgical adhesions in a chimeric mouse model of experimental endometriosis. Fertil Steril 2011, 95:1295-1301.e1

30. Hull ML, Escareno CR, Godsland JM, Doig JR, Johnson CM, Phillips SC, Smith SK, Tavaré S, Print CG, Charnock-Jones DS: Endometrial-peritoneal interactions during endometriotic lesion establishment. Am J Pathol 2008, 173:700-715

31. Filer RB, Wu CH: Coitus during menses. Its effect on endometriosis and pelvic inflammatory disease. J Reprod Med 1989, 34:887-890

32. Hartman CG: How do sperms get into the uterus. Fertil Steril 1957, 8: 403-427

33. Egli GE, Newton M: The transport of carbon particles in the human female reproductive tract. Fertil Steril 1961, 12:151-155

34. Kunz G, Leyendecker G: Uterine peristaltic activity during the menstrual cycle: characterization, regulation, function and dysfunction. Reprod Biomed Online 2002, 4 Suppl 3:5-9

35. Leyendecker G, Kunz G, Wildt L, Beil D, Deininger H: Uterine hyperperistalsis and dysperistalsis as dysfunctions of the mechanism of rapid sperm transport in patients with endometriosis and infertility. Hum Reprod 1996, 11:1542-1551

36. Kunz G, Beil D, Deiniger H, Einspanier A, Mall G, Leyendecker G: The uterine peristaltic pump. Normal and impeded sperm transport within the female genital tract. Adv Exp Med Biol 1997, 424: 267-277

37. Robertson S: Seminal plasma and male factor signalling in the female reproductive tract. Cell Tissue Res 2005, 322:43-52

38. Sharkey DJ, Macpherson AM, Tremellen KP, Mottershead DG, Gilchrist RB, Robertson SA: TGF-beta mediates proinflammatory seminal fluid signaling in human cervical epithelial cells. J Immunol 2012, 189:1024-1035

39. Templeton AA, Cooper I, Kelly RW: Prostaglandin concentrations in the semen of fertile men. J Reprod Fertil 1978, 52:147-150

40. Bujan L, Mieusset R, Audran F, Lumbroso S, Sultan C: Increased oestradiol level in seminal plasma in infertile men. Hum Reprod 1993, 8:74-77

41. Bolitho C, Hahn MA, Baxter RC, Marsh DJ: The chemokine CXCL1 induces proliferation in epithelial ovarian cancer cells by transactivation of the epidermal growth factor receptor. Endocr Relat Cancer 2010, 17:929-940

42. Bilotas M, Meresman G, Buquet R, Sueldo C, Barañao RI: Effect of vascular endothelial growth factor and interleukin-1beta on apoptosis in endometrial cell cultures from patients with endometriosis and controls. J Reprod Immunol 2010, 84:193-198

43. Lebovic DI, Baldocchi RA, Mueller MD, Taylor RN: Altered expression of a cell-cycle suppressor gene, Tob-1, in endometriotic cells by cDNA array analyses. Fertil Steril 2002, 78:849-854

44. Beales IL: Effect of interlukin-1beta on proliferation of gastric epithelial cells in culture. BMC Gastroenterol 2002, 2:7

45. Chegini N, Tang XM, Dou Q: The expression, activity and regulation of granulocyte macrophage-colony stimulating factor in human endometrial epithelial and stromal cells. Mol Hum Reprod 1999, 5: 459-466

46. Hess AP, Nayak NR, Giudice LC: Oviduct and Endometrium: Cyclic Changes in the Primate Oviduct. Edited by Neill JD. New York, Elsevier, 2006, pp 337-382

47. Abbas AR, Baldwin D, Ma Y, Ouyang W, Gurney A, Martin F, Fong S, van Lookeren Campagne M, Godowski P, Williams PM, Chan AC, Clark HF: Immune response in silico (IRIS): immunespecific genes identified from a compendium of microarray expression data. Genes Immun 2005, 6:319-331

48. Chen JC, Johnson BA, Erikson DW, Piltonen TT, Barragan F, Chu S, Kohgadai N, Irwin JC, Greene WC, Giudice LC, Roan NR: Seminal 
plasma induces global transcriptomic changes associated with cell migration, proliferation and viability in endometrial epithelial cells and stromal fibroblasts. Hum Reprod 2014, 29:1255-1270

49. Lebovic DI, Bentzien F, Chao VA, Garrett EN, Meng YG, Taylor RN: Induction of an angiogenic phenotype in endometriotic stromal cell cultures by interleukin-1beta. Mol Hum Reprod 2000, 6: 269-275

50. Rossi M, Sharkey AM, Viganò P, Fiore G, Furlong R, Florio P, Ambrosini G, Smith SK, Petraglia F: Identification of genes regulated by interleukin-1beta in human endometrial stromal cells. Reproduction 2005, 130:721-729

51. Robertson SA, Mau VJ, Hudson SN, Tremellen KP: Cytokineleukocyte networks and the establishment of pregnancy. Am J Reprod Immunol 1997, 37:438-442

52. Robertson SA: GM-CSF regulation of embryo development and pregnancy. Cytokine Growth Factor Rev 2007, 18:287-298

53. Zhan Y, Xu Y, Lew AM: The regulation of the development and function of dendritic cell subsets by GM-CSF: more than a hematopoietic growth factor. Mol Immunol 2012, 52:30-37

54. Punnonen J, Teisala K, Ranta H, Bennett B, Punnonen R: Increased levels of interleukin-6 and interleukin-10 in the peritoneal fluid of patients with endometriosis. Am J Obstet Gynecol 1996, 174: $1522-1526$

55. Ueki M, Tsurunaga T, Ushiroyama T, Ueda M: Macrophage activation factors and cytokines in peritoneal fluid from patients with endometriosis. Asia Oceania J Obstet Gynaecol 1994, 20:427-432

56. Othman Eel-D, Hornung D, Salem HT, Khalifa EA, El-Metwally TH, Al-Hendy A: Serum cytokines as biomarkers for nonsurgical prediction of endometriosis. Eur J Obstet Gynecol Reprod Biol 2008, $137: 240-246$

57. Matalliotakis IM, Goumenou AG, Koumantakis GE, Neonaki MA, Koumantakis EE, Dionyssopoulou E, Athanassakis I, Vassiliadis S: Serum concentrations of growth factors in women with and without endometriosis: the action of anti-endometriosis medicines. Int Immunopharmacol 2003, 3:81-89

58. De Filippo K, Dudeck A, Hasenberg M, Nye E, van Rooijen N, Hartmann K, Gunzer M, Roers A, Hogg N: Mast cell and macrophage chemokines CXCL1/CXCL2 control the early stage of neutrophil recruitment during tissue inflammation. Blood 2013, 121:4930-4937

59. Doyle U, Sampson N, Zenzmaier C, Schwärzler P, Berger P: Seminal plasma enhances and accelerates progesterone-induced decidualisation of human endometrial stromal cells. Reprod Fertil Dev 2012, 24: $517-522$

60. Bischof RJ, Lee CS, Brandon MR, Meeusen E: Inflammatory response in the pig uterus induced by seminal plasma. J Reprod Immunol 1994, 26:131-146

61. Palm F, Walter I, Budik S, Kolodziejek J, Nowotny N, Aurich C: Influence of different semen extenders and seminal plasma on PMN migration and on expression of IL-1beta, IL-6, TNF-alpha and COX2 mRNA in the equine endometrium. Theriogenology 2008, 70: $843-851$

62. Urata Y, Osuga Y, Izumi G, Takamura M, Koga K, Nagai M, Harada M, Hirata T, Hirota Y, Yoshino O, Taketani Y: Interleukinlbeta stimulates the secretion of thymic stromal lymphopoietin (TSLP) from endometrioma stromal cells: possible involvement of TSLP in endometriosis. Hum Reprod 2012, 27:3028-3035

63. Sikora J, Mielczarek-Palacz A, Kondera-Anasz Z: Imbalance in cytokines from interleukin-1 family - role in pathogenesis of endometriosis. Am J Reprod Immunol 2012, 68:138-145

64. Michaud N, Al-Akoum M, Gagnon G, Girard K, Blanchet P, Rousseau JA, Akoum A: Decreased concentrations of soluble interleukin-1 receptor accessory protein levels in the peritoneal fluid of women with endometriosis. J Reprod Immunol 2011, 92:68-73

65. Dziunycz P, Milewski Ł, Radomski D, Barcz E, Kamiński P, Roszkowski PI, Malejczyk J: Elevated ghrelin levels in the peritoneal fluid of patients with endometriosis: associations with vascular endothelial growth factor (VEGF) and inflammatory cytokines. Fertil Steril 2009, 92:1844-1849

66. Bochner BS, Bickel CA, Taylor ML, MacGlashan DW Jr, Gray PW, Raport CJ, Godiska R: Macrophage-derived chemokine induces human eosinophil chemotaxis in a CC chemokine receptor 3- and CC chemokine receptor 4-independent manner. J Allergy Clin Immunol 1999, 103:527-532

67. Godiska R, Chantry D, Raport CJ, Sozzani S, Allavena P, Leviten D, Mantovani A, Gray PW: Human macrophage-derived chemokine (MDC), a novel chemoattractant for monocytes, monocyte-derived dendritic cells, and natural killer cells. J Exp Med 1997, 185:1595-1604

68. Chang Ms, McNinch J, Elias C 3rd, Manthey CL, Grosshans D, Meng T, Boone T, Andrew DP: Molecular cloning and functional characterization of a novel $\mathrm{CC}$ chemokine, stimulated $\mathrm{T}$ cell chemotactic protein (STCP-1) that specifically acts on activated T lymphocytes. J Biol Chem 1997, 272:25229-25237

69. Gleissner CA, von Hundelshausen P, Ley K: Platelet chemokines in vascular disease, arteriosclerosis. Thromb Vasc Biol 2008, 28: $1920-1927$

70. Jones RL, Morison NB, Hannan NJ, Critchley HO, Salamonsen LA: Chemokine expression is dysregulated in the endometrium of women using progestin-only contraceptives and correlates to elevated recruitment of distinct leukocyte populations. Hum Reprod 2005, 20: $2724-2735$

71. Nasu K, Sun B, Nishida M, Fukuda J, Narahara H, Miyakawa I: Cultured human endometrial epithelial cells produce thymus and activation-regulated chemokine with stimulation of interleukin-4 and interleukin-13. Fertil Steril 2004, 82 Suppl 3:1014-1018

72. Oliveira LJ, McClellan S, Hansen PJ: Differentiation of the endometrial macrophage during pregnancy in the cow. PLoS One 2010, 5 : e13213

73. Laudański P, Szamatowicz J, Oniszczuk M: Profiling of peritoneal fluid of women with endometriosis by chemokine protein array. Adv Med Sci 2006, 51:148-152

74. Morris MA, Ley K: Trafficking of natural killer cells. Curr Mol Med 2004, 4:431-438

75. Di Pietro C, Cicinelli E, Guglielmino MR, Ragusa M, Farina M, Palumbo MA, Cianci A: Altered transcriptional regulation of cytokines, growth factors, and apoptotic proteins in the endometrium of infertile women with chronic endometritis. Am J Reprod Immunol 2013, 69:509-517

76. Hamilton SA, Tower CL, Jones RL: Identification of chemokines associated with the recruitment of decidual leukocytes in human labour: potential novel targets for preterm labour. PLoS One 2013, 8: e56946

77. Zhao H, Wang Q, Bai C, He K, Pan Y: A cross-study gene set enrichment analysis identifies critical pathways in endometriosis. Reprod Biol Endocrinol 2009, 7:94

78. Lee KS, Baek DW, Kim KH, Shin BS, Lee DH, Kim JW, Hong YS, Bae YS, Kwak JY: IL-10-dependent down-regulation of MHC class II expression level on monocytes by peritoneal fluid from endometriosis patients. Int Immunopharmacol 2005, 5:1699-1712

79. Thaxton JE, Romero R, Sharma S: TLR9 activation coupled to il-10 deficiency induces adverse pregnancy outcomes. J Immunol 2009, 183:1144-1154

80. Tagashira Y, Taniguchi F, Harada T, Ikeda A, Watanabe A, Terakawa N: Interleukin-10 attenuates TNF-alpha-induced interleukin-6 production in endometriotic stromal cells. Fertil Steril 2009, 91(5 Suppl):2185-2192

81. Tabibzadeh S, Becker JL, Parsons AK: Endometriosis is associated with alterations in the relative abundance of proteins and IL-10 in the peritoneal fluid. Front Biosci 2003, 8:a70-78

82. Podgaec S, Rizzo LV, Fernandes LFC, Baracat EC, Abrao MS: CD4(+) CD25(high) Foxp3(+) cells increased in the peritoneal fluid of patients with endometriosis. Am J Reprod Immunol 2012, 68: 301-308 